\title{
Thyroid nodules update in diagnosis and management
}

\author{
Shrikant Tamhane ${ }^{1 *}$ and Hossein Gharib ${ }^{2,3}$
}

\begin{abstract}
Thyroid nodules are very common. With widespread use of sensitive imaging in clinical practice, incidental thyroid nodules are being discovered with increasing frequency. Their clinical importance is primarily related to the need to exclude malignancy (4.0 to 6.5 percent of all thyroid nodules), assess for their functional status and any pressure symptoms caused by them. New Molecular tests are marketed for the assessment of thyroid nodules for the presence of cancer. The high prevalence of thyroid nodules requires evidence-based rational strategies for their differential diagnosis, risk stratification, treatment, and follow-up. This review addresses advances and controversies in thyroid nodule evaluation, including the new molecular tests, and their management considering the current guidelines and supporting evidence.
\end{abstract}

Keywords: Thyroid, Thyroid Nodules, Molecular markers, Benign, Malignant, FNA, Management, Ultrasonography

\section{Introduction}

Thyroid nodule is a discrete lesion within the thyroid gland that is radiologically distinct from the surrounding thyroid parenchyma. Thyroid nodules are common. They are discovered as an accidental finding by a patient, or as an incidental finding during a routine physical examination in 3 to $7 \%$ [1] or by a radiologic procedure: $67 \%$ with ultrasonography (US) imaging, $15 \%$ with computed tomography (CT) or magnetic resonance imaging (MRI) of the neck, and 1-2 \% with fluorodeoxyglucose (FDG) positron emission tomography. Their clinical importance is primarily related to the need to exclude malignancy (4.0 to 6.5 percent of all thyroid nodules [1-4]), assess for their functional status and any pressure symptoms caused by them.

\section{Diagnosis}

Initial evaluation includes a history, physical examination, and measurement of serum thyroid-stimulating hormone (TSH). Ultrasound is also recommended for all patients to confirm the presence of nodule, define suspicious sonographic features and assess for the presence of additional nodules and lymphadenopathy. Many

\footnotetext{
* Correspondence: Tamhane.Shrikant@Mayo.edu

'Endocrinology and Metabolism, Rochester 55905MN, USA

Full list of author information is available at the end of the article
}

disorders, benign and malignant can cause thyroid nodules (Table 1) $[1,5]$.

Fine needle aspiration (FNA) biopsy is the most accurate method for evaluating thyroid nodules and helps to identify patients who require surgical resection [6]. If a serum TSH is normal or elevated, and the nodule meets criteria for sampling, the next step in the evaluation of a thyroid nodule is a FNA biopsy. Scintigraphy is useful in patients with a low or suppressed serum TSH concentration.

"Work up of thyroid nodule algorithm is presented at the end of the review.

\section{History and physical examination}

With the discovery of a thyroid nodule, a complete history and physical examination focusing on the thyroid gland and adjacent cervical lymph nodes should be performed. Pertinent historical factors predicting malignancy are included in Table $2[1,7]$.

Patients should also be asked about local pressure symptoms such as difficulty in swallowing or difficulty in breathing.

\section{TSH}

Thyroid function should be assessed in all patients with thyroid nodules. 
Table 1 Benign and Malignant causes of thyroid nodules

Benign
Colloid nodule
Hashimoto thyroiditis
Simple or hemorrhagic cyst
Follicular adenoma
Subacute thyroiditis
Malignant
Primary
Follicular cell-derived carcinoma:
$\quad$ PTC, follicular thyroid carcinoma, anaplastic thyroid carcinoma
C-cell-derived carcinoma:
MTC
Thyroid lymphoma
Secondary
Metastatic carcinoma (3 most common primaries are renal, lung
\& head-neck)

If the serum TSH concentration is low, indicating overt or subclinical hyperthyroidism, the possibility that the nodule is hyperfunctioning is increased and thyroid scintigraphy should be performed next using either technetium $99 \mathrm{mTc}$ pertechnetate, or preferably, 123I. If the serum TSH concentration is normal or elevated, and the nodule meets criteria for sampling as will be discussed later, then FNA biopsy is indicated.

\section{Ultrasonography}

Thyroid ultrasound US is noninvasive, relatively inexpensive, and can identify nodules not apparent on physical examination, isotope scanning, or other imaging techniques. It should be performed in all patients with a suspected thyroid nodule, a nodular goiter on physical examination, or with nodules incidentally noted on other

Table 2 Increased risk of malignancy in thyroid nodule

\begin{tabular}{l}
\hline - History of childhood head/neck irradiation \\
- Total body irradiation for bone marrow transplantation [85] \\
- Family history of PTC, MTC, or thyroid cancer syndrome (e.g., \\
Cowden's syndrome, familial polyposis, Carney complex, multiple \\
endocrine neoplasia [MEN] 2, Werner syndrome) in first degree relative \\
- Young age \\
- Male sex \\
- Enlarging nodule \\
- $\quad$ Abnormal cervical adenopathy \\
- $\quad$ Fixed nodule \\
- $\quad$ Vocal cord paralysis \\
\hline
\end{tabular}

imaging studies (carotid ultrasound, CT, MRI, or 18fluorodeoxyglucose [FDG]-PET scan).

Thyroid ultrasonography is used to answer questions about the size and anatomy of the thyroid gland and adjacent structures in the neck.

Sonographic characteristics of a thyroid nodule associated with a higher likelihood of malignancy include hypoechogenicity, increased intranodular vascularity, irregular margins, microcalcifications, absent halo, and a shape taller than wide measured in the transverse dimension [8-13].

A Papillary Thyroid Cancer (PTC) is generally solid or predominantly solid and hypoechoic, often with infiltrative irregular margins and increased nodular vascularity. Microcalcifications, if present, are highly specific for PTC, but may be difficult to distinguish from colloid. Conversely, follicular cancer is more often iso- to hyperechoic and has a thick and irregular halo, but does not have microcalcifications [14]. Follicular cancers that are $<2 \mathrm{~cm}$ in diameter have not been shown to be associated with metastatic disease [15].

Certain sonographic appearances may also be highly predictive of a benign nodule. A pure cystic nodule, although rare ( $<2 \%$ of all nodules), is highly unlikely to be malignant [12]. A spongiform appearance, defined as an aggregation of multiple microcystic components in more than $50 \%$ of the nodule volume, is $99.7 \%$ specific for identification of a benign thyroid nodule $[13,16,17]$.

\section{Scintigraphy}

Thyroid scintigraphy is used to determine the functional status of a nodule. It should be performed in patients with a low serum TSH, indicating overt or subclinical hyperthyroidism.

Scintigraphy utilizes one of the radioisotopes of iodine (usually 123I) or technetium-99 $\mathrm{m}$ pertechnetate. If available, radioiodine scanning is preferred. Normal thyroid follicular cells take up both technetium and radioiodine, but only radioiodine is organified and stored (as thyroglobulin) in the lumen of thyroid follicles [18]. Both radioisotopes are less avidly concentrated by most benign and virtually all malignant thyroid nodules than adjacent normal thyroid tissue. Patients with nodules that are functioning on pertechnetate imaging should undergo radioiodine imaging to confirm that they are actually functioning $[19,20]$ as 5 percent of thyroid cancers concentrate pertechnetate but not radioiodine [18].

\section{Nonfunctioning}

Nonfunctioning nodules with uptake less than surrounding thyroid tissue may require further evaluation by FNA.

\section{Autonomous}

Autonomous nodules may appear hot (uptake is greater than surrounding thyroid tissue) if they are hyperfunctioning. Autonomous nodules that do not make sufficient 
thyroid hormone to suppress serum TSH concentrations will appear indeterminate on thyroid scintigraphy. Autonomous nodules account for only 5 to 10 percent of palpable nodules. Only a few patients with autonomous nodules have been found to have thyroid cancer [21-23], and only a few of these cancers were aggressive [24]. Since hyperfunctioning nodules rarely are cancer, a nodule that is hyperfunctioning on radioiodine imaging does not require FNA.

\section{Indeterminate}

Scintigraphy is two-dimensional, its limitations result from the superimposition of abnormal nodular tissue and normally functioning thyroid tissue. Thus, while over 80 percent of nonautonomous nodules greater than $2 \mathrm{~cm}$ appear cold, smaller nodules present as a filling defect in less than one-third of cases [22]. The remaining majority of smaller nodules are indeterminate on thyroid scintigraphy [25]. They could represent either small non-functioning nodules anterior or posterior to normally functioning thyroid tissue, or autonomous nodules that do not produce sufficient thyroid hormone to suppress TSH.

Most indeterminate nodules should be evaluated by FNA.

\section{Fine needle aspiration biopsy}

FNA is the most accurate and cost-effective method for evaluating thyroid nodules and is the procedure of choice for evaluating thyroid nodules and selecting candidates for surgery [26-37].

FNA is a simple and safe office procedure in which tissue samples are obtained for cytologic examination using 23 to 27 gauge needles with or without local anesthesia.

\section{Palpation-guided fine-needle aspiration}

Detailed descriptions of the palpation-guided FNA procedure, its problems, and progress to date have been published elsewhere [26-28, 31-35, 37].

\section{Ultrasound-guided fine-needle aspiration}

Commercially available US machines equipped with 7.5to $10.0-\mathrm{MHz}$ transducers give a clear, concise, and continuous visualization of the thyroid gland and permit real-time visualization of the needle tip during the FNA procedure to ensure accurate sampling of the desired area.

ATA guidelines recommend Ultrasound-guided FNA biopsy for nonpalpable nodules and for nodules that are technically difficult to aspirate using palpation methods alone, such as predominantly cystic or posteriorly located nodules. In patients with large nodules $(>4 \mathrm{~cm})$, ultrasound-guided FNA directed at several areas within the nodule may reduce the risk of a false negative biopsy.

\section{Indications}

There is increasing evidence that the presence of suspicious ultrasound features is more predictive of malignancy than nodule size alone $[8,9]$. Thyroid nodules < $1 \mathrm{~cm}$ in diameter should not be subjected to FNA, even if suspicious. A decision analysis of thyroid nodule biopsy criteria for nodules measuring 1.0 to $1.5 \mathrm{~cm}$ favors the approach of selecting nodules with suspicious ultrasonographic characteristics for biopsy over the approach of biopsy for all nodules $\geq 1 \mathrm{~cm}$ (Table 3) [38].

FNA biopsy is recommended for solid hypoechoic nodules (palpable or nonpalpable) measuring $>1 \mathrm{~cm}$. This recommendation is based upon observational studies that show similar rates of cancer in nonpalpable nodules $>1 \mathrm{~cm}$ and palpable nodules of similar size [10, 39]. FNA is also recommended for solid nodules that are isoechoic or hyperechoic, if they are $\geq 1.0$ to $1.5 \mathrm{~cm}$, and for mixed cystic-solid nodules without suspicious features on ultrasound, if they are $\geq 2.0 \mathrm{~cm}$. Mixed cystic-solid nodules and predominantly cystic with $>50 \%$ cystic component are generally evaluated by FNA with directed biopsy of the solid component (especially the vascular component). Cyst drainage may also be performed, especially in symptomatic patients [40]. Spongiform nodules, defined as an aggregation of multiple microcystic components in more than 50 percent of the nodule volume, may not require FNA regardless of size, although it may be prudent to biopsy spongiform nodules $>2.0 \mathrm{~cm}$. Purely cystic nodules (no mural component) do not require a biopsy.

Although routine FNA is not recommended for subcentimeter nodules, there are exceptions. The presence of a solid hypoechoic nodule with microcalcifications is highly suggestive of PTC. Although most micropapillary carcinomas may be incidental findings, a subset may be more clinically relevant, especially those $>5 \mathrm{~mm}$ in diameter [41]. These include nodules that have abnormal lymph nodes detected clinically or with imaging at presentation $[42,43]$. Other groups of patients with a higher likelihood of malignancy (high risk history) include: 1) family history of PTC [44]; 2) history of external beam radiation exposure as a child [45]; 3) exposure to ionizing

Table 3 [8-10, 26-40, 86]: FNA recommendations for diagnostic FNA based on sonographic features

A. Nodules $\geq 1 \mathrm{~cm}$ with high suspicion sonographic pattern

B. Nodules $\geq 1 \mathrm{~cm}$ with intermediate suspicion sonographic pattern

C. Nodules $\geq 1.5 \mathrm{~cm}$ with low suspicion sonographic pattern

D. Nodules $\geq 2 \mathrm{~cm}$ with very low suspicion sonographic pattern (e.g., spongiform)

E. FNA is not required for thyroid nodules that do not meet the above criteria, including all nodules $<1 \mathrm{~cm}$

F. FNA is not required for purely cystic nodules 
radiation in childhood or adolescence [46]; and 4) 18FDGPET-positive thyroid nodules. Periodic ultrasonography (initially in 6 to 12 months, then at increasing intervals over time assuming stability, e.g., at one to two year intervals, then three to five years) to evaluate for growth is a reasonable approach [8].

Patients with multiple nodules have the same risk of malignancy as those with a single nodule $[9,47]$. Thus, the sonographic features of each nodule should be assessed independently to determine the need for FNA biopsy. If there are multiple coalescent nodules and none have suspicious sonographic features, FNA biopsy of the largest nodule is reasonable [40]. The nodules that are not biopsied should be monitored with periodic ultrasonography.

\section{Cytological diagnosis}

The National Cancer Institute Thyroid Fine Needle Aspiration State of the Science Conference ("Bethesda Conference") suggests the following classification scheme [48]:

- Benign - This includes macrofollicular or adenomatoid/hyperplastic nodules, colloid adenomas, nodular goiter, and Hashimoto's thyroiditis

- Follicular lesion or atypia of undetermined significance (FLUS or AUS) - This includes lesions with atypical cells, or mixed macro- and microfollicular nodules

- Follicular neoplasm - This includes microfollicular nodules, including Hürthle cell lesions

- Suspicious for malignancy

- Malignant

- Nondiagnostic

FNA results are categorized as diagnostic (satisfactory) or nondiagnostic (unsatisfactory). The specimen is "diagnostic," "adequate," or "satisfactory" if it contains no less than six groups of well-preserved thyroid epithelial cells consisting of at least 10 cells in each group.

Benign (negative) cytology, the most common finding, is indicative of a colloid nodule, macrofollicular adenoma, lymphocytic thyroiditis, granulomatous thyroiditis, or benign cyst [29]. The most common benign diagnosis is "colloid nodule," which may come from a normal thyroid gland, a benign nodule, a MNG, or a macrofollicular adenoma. Malignant (positive) results are reliably identified by an experienced cytopathologist; the cytopathologist's expertise in thyroid cytology is crucial in ensuring proper interpretation of smears [26, 28, 32]. PTC is the most common malignancy; other malignant lesions include MTC, anaplastic carcinoma, and highgrade metastatic cancers [28]. Suspicious (indeterminate) specimens are those for which a clear cytologic diagnosis cannot be made $[26,28,30]$ and include follicular neoplasms, Hurthle cell neoplasms, atypical PTC, or lymphoma.

Nondiagnostic or unsatisfactory smears with an inadequate number of cells result from acellular cystic fluid, bloody smears, or poor techniques in preparing slides $[29,31]$. Nondiagnostic aspirates have few or no epithelial cells for proper cytodiagnosis and account for up to $20 \%$ of all specimens $[31,49,50]$. The criteria for judging aspirates as inadequate are somewhat arbitrary and are influenced by the standards of a given laboratory, the nature of the cystic nodule, and the expertise of the cytopathologist.

Overall, $70 \%$ of FNA specimens are benign, $5 \%$ malignant, $10 \%$ suspicious, and $15 \%$ unsatisfactory $[26-28,32,51]$. The final FNA report is critical in dictating whether the patient's management should be medical or surgical.

\section{Molecular markers}

Approximately 10 - $25 \%$ of fine needle aspiration biopsies yield an indeterminate result with the risk of malignancy varying from $5 \%$ to $75 \%$ (typically 15-30\%) depending on the indeterminate category according to the Bethesda System for Reporting Thyroid Cytopathology [52]. However, most patients (75 to 95 percent) undergo surgery for what is ultimately confirmed to be benign disease. Recent advances in thyroid and cancer biology have led to the development and marketing of several tests to assist in determining whether a nodule with indeterminate cytology, follicular lesion/atypia of undetermined significance or follicular neoplasm, is benign or malignant.

At present, two main types of molecular tests are marketed for the assessment of thyroid nodules for the presence of cancer. These tests, Veracyte's Afirma geneexpression classifier, and mutation analysis panels such as ThygenX (earlier Asuragen's miRInform), ThyroSeq ${ }^{\circ}$ v.2 Next Generation Sequencing panel (CBLPath, Ocala, FL) [53], Quest Diagnostic's panel and other similar panels, utilize different methods to assess the risk of malignancy. A third type test from the Cleveland Clinic utilizing serum TSH receptor mRNA levels is also available commercially, but has received less scrutiny in the medical literature [54].

The Afirma gene-expression classifier is based on the gene expression profiles of surgically proven benign and malignant thyroid nodules and evaluates for the presence of a benign gene expression profile. Based on validation studies demonstrating high negative predictive value among nodules with cytology of AUS/FLUS or FN/SFN, it has been employed as a "Rule Out" test to identify nodules that are benign [55]. However, since a substantial number of benign nodules do not have a gene expression profile classified as benign, this test 
cannot reliably "Rule In" the presence of malignancy. As a "Rule Out" test, the Afirma gene expression classifier has been reported to obviate the need for surgical excision in over $60 \%$ of cases [56].

The ThygenX mutation analysis panel assesses for BRAF and RAS point mutations as well as common rearrangements of RET/PTC and PAX8/PPAR $\gamma$. It is estimated that one of these mutations is present in approximately $70 \%$ of well-differentiated thyroid cancers. ThygenX mutation analysis panel is considered a "Rule In" assay as nodules harboring these mutations or rearrangements have a high likelihood of cancer giving this test's high positive predictive value [57]. However, as a significant number of malignant nodules do not harbor one of these genetic markers, the ThygenX panel cannot reliably "Rule Out" cancer. Additionally, RAS mutations can be commonly found in benign adenomas. Of note, the components of the test are available as stand-alone assays or in various combinations by other laboratories, e.g. Quest Diagnostics.

The mutation analysis panels and Afirma test are performed using samples from needle washings collected during fine needle aspiration biopsy.

Molecular testing is just one of many factors that must be considered in the evaluation of a thyroid nodule. None of the presently available tests is associated with a $100 \%$ negative or positive predictive value (NPV or PPV). Thus, no currently available molecular test identifies the absence or presence of malignancy in all indeterminate nodules. Before utilizing these expensive tests, one should also consider the sonographic characteristics and the size of the nodule, the degree of patient concern, and the availability of follow-up imaging. Molecular testing should only be used to complement and not to replace cytopathologic evaluation or clinical and imaging assessment. As molecular testing is new and advances in the field are regularly occurring, clinicians need to stay informed as recommendations for use within practice are expected to evolve.

\section{Serum calcitonin concentration}

The routine measurement of serum calcitonin in patients with nodular thyroid disease is controversial [58].

The utility of serum calcitonin has been evaluated in a series of prospective, non-randomized studies [59-62]. The data suggest that the use of routine serum calcitonin for screening may detect C-cell hyperplasia and medullary thyroid cancer at an earlier stage and overall survival may be improved. However, most studies rely on pentagastrin stimulation testing to increase specificity. This drug is no longer available in the United States, and there remain unresolved issues of sensitivity, specificity, assay performance and cost-effectiveness. Falsepositive calcitonin results may be obtained in patients with hypercalcemia, hypergastrinemia, neuroendocrine tumors, renal insufficiency, papillary and follicular thyroid carcinomas, goiter, and chronic autoimmune thyroiditis [6, 63]. Prolonged treatment with omeprazole (greater than two to four months), beta-blockers, and glucocorticoids have been associated with hypercalcitoninemia [64]. In addition, there are reports of rare MTCs that do not secrete calcitonin, and a false negative test result may be expected $[65,66]$.

If pentagastrin stimulation testing were available, some thyroid experts would routinely measure serum calcitonin in patients with nodular thyroid disease, whereas others would not. There is a growing interest in using the calcium stimulation test as a confirmatory test in patients with elevated basal calcitonin levels. However, few standardized data using modern calcitonin assays are available $[67,68]$.

Controversy remains about the routine use of serum calcitonin measurements because of the absence of uniform calcitonin thresholds to distinguish sporadic occult MTC [69-71], the high false-positive rate (59 percent or higher) in some studies, and the uncertain importance of small tumors $[6,72]$.

Given the uncertainties surrounding calcitonin measurements, ATA and has not taken a position for or against calcitonin screening $[40,73]$.

\section{Other lab tests}

Routine measurement of serum anti-thyroid peroxidase (TPO) antibodies and Thyroglobulin is not necessary.

\section{Pregnancy}

Thyroid radionuclide scanning is contraindicated during pregnancy. For women with suppressed serum TSH levels that persist after the first trimester, FNA may be deferred until after pregnancy and cessation of lactation, when a radionuclide scan can be performed to evaluate nodule function [40]. Otherwise, a pregnant woman found to have a thyroid nodule should be evaluated in the same way as if she were not pregnant. Thus, FNA biopsy of the nodule should be done (as it would be for most nonpregnant patients).

ATA guidelines recommend monitoring of a nodule with cytology indicating PTC discovered early in pregnancy sonographically and if it grows substantially (as defined above) by 24 weeks gestation, surgery should be performed at that point. However, if it remains stable by midgestation or if it is diagnosed in the second half of pregnancy, surgery may be performed after delivery. In patients with more advanced disease, surgery in the second trimester is reasonable.

In pregnant women with FNA that is suspicious for or diagnostic of PTC, consideration could be given to 
administration of levothyroxine therapy to keep the TSH in the range of $0.1-1 \mathrm{mU} / \mathrm{L}$.

\section{MANAGEMENT}

Clinical management of thyroid nodules is influenced by the combined results of TSH measurement, FNA biopsy, and US and depends primarily on cytologic diagnosis. There are six major categories of results that are obtained from fine needle aspiration (FNA), each of which indicates different subsequent management.

\section{Benign nodules}

(Patients with benign nodules (macrofollicular or adenomatoid/hyperplastic nodules, colloid adenomas, nodular goiter, and Hashimoto's thyroiditis) are usually followed without surgery. There is still controversy concerning the efficacy of thyroxine (T4) therapy for these patients. In the absence of a history of childhood neck irradiation, patients with benign nodules should not be treated with $\mathrm{T} 4$.

It is recommended thyroid nodules be followed with serial US examinations 6-18 months after the initial evaluation [40]. If nodule size is stable (i.e., no more than a $50 \%$ change in volume or $<20 \%$ increase in at least two nodule dimensions in solid nodules or in the solid portion of mixed cystic-solid nodules), the interval before the next follow-up clinical examination or US may be longer, e.g., every $3-5$ years; if otherwise, the FNA should be repeated, preferably with US guidance.

Malignancy is rare even in benign thyroid nodules that have grown [74]. Cystic degeneration and hemorrhage are the most common causes of sudden enlargement, and can be detected by ultrasonography or repeat aspiration [25]. The appropriate interval for ultrasound monitoring is uncertain, as there are few studies that examine this issue. In a retrospective cohort study of 1369 patients with 2010 cytologically benign nodules, followed for an average of 8.5 years, there were no deaths attributable to thyroid illness or thyroid cancer [75]. If supported by further prospective studies, these data suggest that less frequent monitoring of cytologically benign nodules may be warranted.

\section{Follicular lesion or atypia of undetermined significance}

This category includes lesions with mild nuclear atypia, mixed macrofollicular and microfollicular lesions where the proportion of microfollicles and macrofollicles is similar, lesions with extensive oncocytic (Hürthle cell) change, and specimens that are compromised because of poor fixation or obscuring blood. The risk of malignancy with this cytologic classification ranges from 5 to 32 percent [76-78]. There is no definite consensus as to which of these should be excised to exclude follicular cancer.

One approach is to follow patients with nodules that are greater than 50 percent macrofollicular fragments (flat sheets with uniform non-crowded cells), unless they are clinically suspicious or present in patients with a higher risk of cancer. Nodules that are less than 50 percent macrofollicular fragments, nodules with similar proportions of macrofollicles and microfollicles, and nodules with cellular atypia are frequently reaspirated after a three to six month interval, or earlier, before making a decision whether to monitor or excise [8]. If repeat aspirates continue to show atypical cells or microfollicularity, surgery, or molecular testing (as for follicular neoplasm) should be considered.

\section{Follicular neoplasm}

Several approaches are now available or under investigation to improve upon cytology alone for the assessment of follicular neoplasm and follicular lesion/atypia of undetermined significance.

In patients with cytology suggesting follicular neoplasms (microfollicular, cellular, or indeterminate), if the thyroid-stimulating hormone (TSH) is in the lower end of the normal range $(<1 \mathrm{mU} / \mathrm{mL})$, thyroid scintigraphy would be the next step. Patients with hyperfunctioning (autonomous) nodules are followed, or if the patient is hyperthyroid, radioiodine therapy or surgery is advised.

For patients with nonfunctioning nodules and TSH levels $>1 \mathrm{mU} / \mathrm{mL}$, where available, either a mRNA classifier system (gene expresser classifier) or mutational analysis (using a broad next-generation sequencing assay with an expanded panel of point mutations and gene fusions) for further evaluating FNA aspirates with indeterminate cytology (follicular neoplasm or follicular lesion/ atypia of undetermined significance is suggested.

If molecular diagnostic testing is not available, diagnostic thyroid lobectomy would be the next step. From 15 to 25 percent of microfollicular or cellular adenomas prove to be cancers, depending upon the cytologic pattern [48]. Patients with surgical histology specimens showing benign follicular adenoma (ie, the absence of capsular or vascular invasion) do not require further treatment. However, patients whose surgical histology shows follicular thyroid cancer (or follicular variant papillary thyroid cancer) might need to have a completion thyroidectomy.

The routine use of molecular analysis on indeterminate FNA aspirates (follicular neoplasm or follicular lesion/ atypia of undetermined significance) has reduced substantially the number of patients who are referred for diagnostic thyroid surgery. Long-term data utilizing molecular testing, however, are still lacking.

\section{Suspicious for malignancy}

This category includes lesions with some features suggestive of but not definitive for papillary thyroid cancer. Typically, nodules in this category have a 50 to 75 percent risk of malignancy. Such patients should be referred for surgery. 


\section{Malignant}

The malignant category includes papillary cancer, medullary cancer, thyroid lymphoma, anaplastic cancer, and cancer metastatic to the thyroid. Patients with cytology diagnostic of malignancy should be referred for surgery. If cytologic results are positive for primary thyroid malignancy, surgery is almost always needed [40, 51, 79, 80]. Cancer due to metastasis requires further investigations aimed at finding the primary lesion, which often precludes thyroid surgery. If preoperative FNA results suggest PTC, a near-total or total thyroidectomy is preferred [40, 51, 81, 82]. With the exception of intrathyroidal microcarcinomas with no evidence of nodal involvement, lymph nodes within the central compartment of the neck (level 6) should be removed $[40,51,79]$. It is recommended that all patients undergoing thyroid surgery be evaluated by US preoperatively [40]. Abnormal lymph nodes identified by US should be removed and sent for pathologic examination at cervical exploration.

\section{Nondiagnostic}

A nondiagnostic biopsy is cytologically inadequate. It is critical that the absence of malignant cells not be interpreted as a negative biopsy if no or scant follicular tissue is obtained for patients with nondiagnostic FNA, FNA using ultrasound-guidance should be repeated [40]. If still nondiagnostic, core needle biopsy should be considered. Surgical excision, especially for larger solid nodules with sonographically suspicious features [83], or observation, especially for smaller partially cystic nodules, are reasonable options.

Partially cystic nodules that repeatedly yield nondiagnostic aspirates need close observation or surgical excision. Surgery should be more strongly considered if the cytologically nondiagnostic nodule is solid [40].

\section{Autonomous nodules}

The optimal therapy of patients with autonomous nodules is controversial. Those in whom the nodule causes hyperthyroidism should be treated with radioiodine or surgery, possibly after a period of antithyroid drug therapy.

Patients with subclinical hyperthyroidism (low serum $\mathrm{TSH}$ and normal serum free T4 values) present a difficult problem. Subclinical hyperthyroidism is associated with an increased risk of atrial fibrillation in patients over age 60 to 65 years, and in postmenopausal women, a decrease in bone mineral density. Management depends upon clinical risk for complications of subclinical hyperthyroidism and the degree of TSH suppression.

\section{Ablation techniques}

Benign, solid or cystic thyroid nodules, sometimes become symptomatic and warrant treatment. A recent comprehensive review has compared advantages and disadvantages, plus cost considerations, of minimally-invasive procedures vis-a-vis surgical treatment of benign thyroid masses [84].

\section{Summary}

Thyroid nodules are common and carry a 4-6.5\% risk of malignancy. The initial evaluation in all patients with a thyroid nodule includes a history, physical examination, neck ultrasonography, and measurement of serum TSH. Fine needle aspiration (FNA) biopsy is the most accurate method for evaluating thyroid nodules. Nodules with diameter $<1 \mathrm{~cm}$ require no FNA and can be observed with a follow up US. Patients with benign nodules are usually followed without surgery. Where available, mRNA classifier system or mutational analysis can be used for further evaluating FNA aspirates with cytology of follicular neoplasm or follicular lesion/ atypia of undetermined significance. Patients with cytology suggesting cancer or suspicious for cancer should be referred for surgery. The high prevalence of thyroid nodules requires evidence-based rational strategies for their differential diagnosis, risk stratification, treatment, and follow-up. As more evidence becomes available, active surveillance may become possible for selected cases of thyroid cancer patients.

\section{Thyroid Nodule Workup Algorithm}

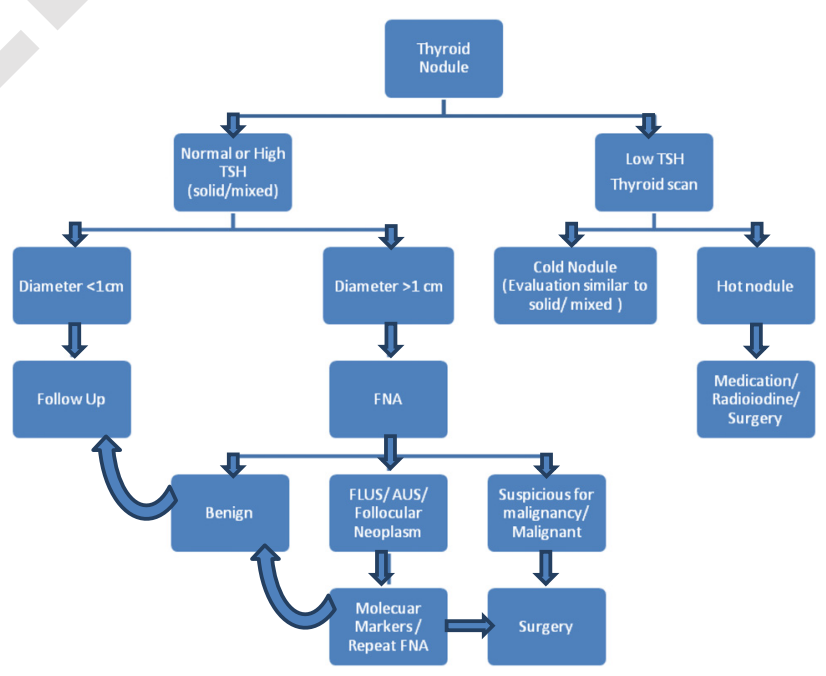

Competing interests

All authors declare that they have no competing interests.

\section{Authors' contributions}

ST did the literature search and drafted the review. The final content and format was finalized aftermultiple discussions between the authors ST and HG. HG also provided constant input in terms of articles andstructure and did the final revision of the review. Both authors read and approved the final manuscript.

\section{Author details}

${ }^{1}$ Endocrinology and Metabolism, Rochester 55905MN, USA. ²Mayo Clinic College of Medicine, Rochester 55905MN, USA. ${ }^{3}$ Division of Endocrinology, 
Diabetes, Metabolism, and Nutrition, Mayo Clinic, 200 First Street SW, Rochester 55905MN, USA.

\section{Received: 28 May 2015 Accepted: 9 July 2015 Published online: 18 September 2015}

\section{References}

1. Hegedüs L. Clinical practice. The thyroid nodule. N Engl J Med. 2004;351:1764

2. Werk Jr EE, Vernon BM, Gonzalez JJ, Ungaro PC, McCoy RC. Cancer in thyroid nodules. A community hospital survey. Arch Intern Med. 1984;144:474.

3. Belfiore A, Giuffrida D, La Rosa GL, Ippolito O, Russo G, Fiumara A, et al. High frequency of cancer in cold thyroid nodules occurring at young age. Acta Endocrinol (Copenh). 1989:121:197.

4. Lin JD, Chao TC, Huang BY, Chen ST, Chang HY, Hsueh C. Thyroid cancer in the thyroid nodules evaluated by ultrasonography and fine-needle aspiration cytology. Thyroid. 2005;15:708.

5. Tan GH, Gharib H. Thyroid incidentalomas: management approaches to nonpalpable nodules discovered incidentally on thyroid imaging. Ann Intern Med. 1997;126(3):226-31.

6. Castro MR, Gharib H. Continuing controversies in the management of thyroid nodules. Ann Intern Med. 2005;142:926.

7. RossDM. Diagnostic approach to and treatment of thyroid nodules. I. In: Rose BD, editor. Wellesley (MA): UpToDate; 2005.

8. Leenhardt L, Hejblum G, Franc B, Fediaevsky LD, Delbot T, Le Guillouzic D, et al. Indications and limits of ultrasound-guided cytology in the management of nonpalpable thyroid nodules. J Clin Endocrinol Metab. 1999:84:24-8.

9. Papini E, Guglielmi R, Bianchini A, Crescenzi A, Taccogna S, Nardi F, et al. Risk of malignancy in nonpalpable thyroid nodules: predictive value of ultrasound and color-Doppler features. J Clin Endocrinol Metab. 2002;87:1941-6.

10. Nam-Goong IS, Kim HY, Gong G, Lee HK, Hong SJ, Kim WB, et al. Ultrasonography-guided fine-needle aspiration of thyroid incidentaloma: correlation with pathological findings. Clin Endocrinol (Oxf ). 2004;60:21-8.

11. Cappelli C, Castellano M, Pirola I, Cumetti D, Agosti B, Gandossi E, et al. The predictive value of ultrasound findings in the management of thyroid nodules. QJM. 2007;100:29-35.

12. Frates MC, Benson CB, Doubilet PM, Kunreuther E, Contreras M, Cibas ES, et al. Prevalence and distribution of carcinoma in patients with solitary and multiple thyroid nodules on sonography. J Clin Endocrinol Metab. 2006;91:3411-7.

13. Moon WJ, Jung SL, Lee JH, Na DG, Baek JH, Lee YH, et al. Thyroid Study Group, Korean Society of Neuro- and Head and Neck Radiology. Benign and malignant thyroid nodules: US differentiation - multicenter retrospective study. Radiology. 2008;247:762-70.

14. Jeh SK, Jung SL, Kim BS, Lee YS. Evaluating the degree of conformity of papillary carcinoma and follicular carcinoma to the reported ultrasonographic findings of malignant thyroid tumor. Korean J Radiol. 2007:8:192-7.

15. Machens A, Holzhausen HJ, Dralle $H$. The prognostic value of primary tumor size in papillary and follicular thyroid carcinoma. Cancer. 2005;103:2269-73

16. Moon WJ, Kwag HJ, Na DG. Are there any specific ultrasound findings of nodular hyperplasia ("leave me alone" lesion) to differentiate it from follicular adenoma? Acta Radiologica. 2009;50:383-8.

17. Bonavita JA, Mayo J, Babb J, Bennett G, Oweity T, Macari M, et al. Pattern recognition of benign nodules at ultrasound of the thyroid: which nodules can be left alone? AJR Am J Roentgenol. 2009;193:207-13.

18. Reschini E, Ferrari C, Castellani M, Matheoud R, Paracchi A, Marotta G, et al. The trapping-only nodules of the thyroid gland: prevalence study. Thyroid. 2006;16:757

19. Shambaugh 3rd GE, Quinn JL, Oyasu R, Freinkel N. Disparate thyroid imaging. Combined studies with sodium pertechnetate TC $99 \mathrm{~m}$ and radioactive iodine. JAMA. 1974;228:866.

20. Blum M, Goldman AB. Improved diagnosis of "nondelineated" thyroid nodules by oblique scintillation scanning and echography. J Nucl Med. 1975;16:713.

21. Nelson RL, Wahner HW, Gorman CA. Rectilinear thyroid scanning as a predictor of malignancy. Ann Intern Med. 1978;88:41.
22. Miller JM. Re: thyroid carcinoma in an autonomously functioning nodule. J Nucl Med. 1980:21:296.

23. Hoving J, Piers DA, Vermey A, Oosterhuis JW. Carcinoma in hyperfunctioning thyroid nodule in recurrent hyperthyroidism. Eur J Nucl Med. 1981;6:131.

24. Hayes FJ, Sheahan K, Heffernan A, McKenna TJ. Aggressive thyroid cancer associated with toxic nodular goitre. Eur J Endocrinol. 1996;134:366.

25. Ashcraft MW, Van Herle AJ. Management of thyroid nodules. II: Scanning techniques, thyroid suppressive therapy, and fine needle aspiration. Head Neck Surg. 1981;3:297.

26. Gharib H. Fine-needle aspiration biopsy of thyroid nodules: advantages, limitations, and effect. Mayo Clin Proc. 1994;69(1):44-9.

27. Goellner JR, Gharib H, Grant CS, Johnson DA. Fine needle aspiration cytology of the thyroid, 1980 to 1986. Acta Cytol. 1987;31(5):587-90.

28. Gharib H, Goellner JR. Fine-needle aspiration biopsy of thyroid nodules. Endocr Pract. 1995;1(6):410

29. Gharib H, Goellner JR, Zinsmeister AR, Grant CS, Van Heerden JA. Fine-needle aspiration biopsy of the thyroid: the problem of suspicious cytologic findings. Ann Intern Med. 1984;101(1):25-8.

30. Cersosimo E, Gharib H, Suman VJ, Goellner JR. "Suspicious" thyroid cytologic findings: outcome in patients without immediate surgical treatment. Mayo Clin Proc. 1993;68(4):343-8.

31. Chow LS, Gharib H, Goellner JR. Nondiagnostic thyroid fine-needle aspiration cytology: management dilemmas. Thyroid. 2001;11(12):1147-51.

32. Gharib H, Goellner JR. Fine-needle aspiration biopsy of the thyroid: an appraisal. Ann Intern Med. 1993;118(4):282-9.

33. Caruso D, Mazzaferri EL. Fine needle aspiration biopsy in the management of thyroid nodules. Endocrinologist. 1991;1:1194-202.

34. Castro MR, Gharib H. Thyroid fine-needle aspiration biopsy: progress, practice, and pitfalls. Endocr Pract. 2003;9(2):128-36.

35. Jeffrey PB, Miller TR. Fine-needle aspiration cytology of the thyroid. Pathology (Phila). 1996:4(2):319-35.

36. Hamberger B, Gharib H, Melton III $\sqcup$, Goellner JR, Zinsmeister AR. Fine-needle aspiration biopsy of thyroid nodules: impact on thyroid practice and cost of care. Am J Med. 1982;73(3):381-4.

37. Hamburger Jl, Hamburger SW. Fine needle biopsy of thyroid nodules: avoiding the pitfalls. NY State J Med. 1986;86(5):241-9.

38. McCartney CR, Stukenborg GJ. Decision analysis of discordant thyroid nodule biopsy quideline criteria. J Clin Endocrinol Metab. 2008;93:3037.

39. Hagag P, Strauss S, Weiss M. Role of ultrasound-guided fine-needle aspiration biopsy in evaluation of nonpalpable thyroid nodules. Thyroid. 1998:8:989.

40. American Thyroid Association (ATA) Guidelines Taskforce on Thyroid Nodules and Differentiated Thyroid Cancer, Cooper DS, Doherty GM, Haugen BR, Kloos RT, Lee SL, et al. Revised American Thyroid Association management guidelines for patients with thyroid nodules and differentiated thyroid cancer. Thyroid. 2009;19:1167.

41. Noguchi S, Yamashita H, Uchino S, Watanabe S. Papillary microcarcinoma. World J Surg. 2008;32:747-53.

42. Wada N, Duh QY, Sugino K, Iwasaki H, Kameyama K, Mimura T, et al. Lymph node metastasis from 259 papillary thyroid microcarcinomas: frequency, pattern of occurrence and recurrence, and optimal strategy for neck dissection. Ann Surg. 2003;237:399-407.

43. Ito Y, Tomoda C, Uruno T, Takamura Y, Miya A, Kobayashi K, et al. Preoperative ultrasonographic examination for lymph node metastasis: usefulness when designing lymph node dissection for papillary microcarcinoma of the thyroid. World J Surg. 2004:28:498-501.

44. Hemminki K, Eng C, Chen B. Familial risks for nonmedullary thyroid cancer. J Clin Endocrinol Metab. 2005:90:5747-53.

45. Schneider AB, Ron E, Lubin J, Stovall M, Gierlowski TC. Dose-response relationships for radiation-induced thyroid cancer and thyroid nodules: evidence for the prolonged effects of radiation on the thyroid. J Clin Endocrinol Metab. 1993;77:362-9.

46. Shibata Y, Yamashita S, Masyakin VB, Panasyuk GD, Nagataki S. 15 years after Chernobyl: new evidence of thyroid cancer. Lancet. 2001;358:1965-6.

47. Marqusee E, Benson CB, Frates MC, Doubilet PM, Larsen PR, Cibas ES, et al. Usefulness of ultrasonography in the management of nodular thyroid disease. Ann Intern Med. 2000;133:696.

48. Baloch ZW, LiVolsi VA, Asa SL, Rosai J, Merino MJ, Randolph G, et al. Diagnostic terminology and morphologic criteria for cytologic diagnosis of thyroid lesions: a synopsis of the National Cancer Institute Thyroid Fine-Needle Aspiration State of the Science Conference. Diagn Cytopathol. 2008;36:425. 
49. Schmidt T, Riggs MW, Speights Jr VO. Significance of nondiagnostic fine-needle aspiration of the thyroid. South Med J. 1997;90(12):1183-6.

50. McHenry CR, Walfish PG, Rosen IB. Non-diagnostic fine needle aspiration biopsy: a dilemma in management of nodular thyroid disease. Am Surg. 1993;59:7.

51. Gharib H, Papini E, Paschke R, Duick DS, Valcavi R, Hegedüs L, et al. AACE/AME/ ETA Thyroid Nodule Guidelines. Endocr Pract. 2010;16(1):1-43.

52. Bongiovanni M, Spitale A, Faquin WC, Mazzucchelli L, Baloch ZW. The Bethesda system for reporting thyroid cytopathology: a meta-analysis. Acta Cytol. 2012;56:333-9.

53. Nikiforov YE, Carty SE, Chiosea SI, Coyne C, Duwvuri U, Ferris RL, et al. Highly accurate diagnosis of cancer in thyroid nodules with follicular neoplasm/ suspicious for a follicular neoplasm cytology by ThyroSeq v2 next-generation sequencing assay. Cancer. 2014;120(23):3627-34.

54. Keutgen XM, Filicori F, Fahey 3rd TJ. Molecular diagnosis for indeterminate thyroid nodules on fine needle aspiration: advances and limitations. Expert Rev Mol Diagn. 2013;13(6):613-23.

55. Alexander EK, Kennedy GC, Baloch ZW, Cibas ES, Chudova D, Diggans J, et al. Preoperative diagnosis of benign thyroid nodules with indeterminate cytology. N Engl J Med. 2012;367:705-15.

56. Li H, Robinson KA, Anton B, Saldanha IJ, Ladenson PW. Cost-effectiveness of a novel molecular test for cytologically indeterminate thyroid nodules. J Clin Endocrinol Metab. 2011;96, E1719.

57. Nikiforov YE, Ohori NP, Hodak SP, Carty SE, LeBeau SO, Ferris RL, et al. Impact of mutational testing on the diagnosis and management of patients with cytologically indeterminate thyroid nodules: a prospective analysis of 1056 FNA samples. J Clin Endocrinol Metab. 2011;96:3390-7.

58. Costante G, Filetti S. Early diagnosis of medullary thyroid carcinoma: is systematic calcitonin screening appropriate in patients with nodular thyroid disease? Oncologist. 2011;16:49.

59. Elisei R, Bottici V, Luchetti F, Di Coscio G, Romei C, Grasso L, et al. Impact of routine measurement of serum calcitonin on the diagnosis and outcome of medullary thyroid cancer: experience in 10,864 patients with nodular thyroid disorders. J Clin Endocrinol Metab. 2004;89:163-8.

60. Hahm JR, Lee MS, Min YK, Lee MK, Kim KW, Nam SJ, et al. Routine measurement of serum calcitonin is useful for early detection of medullary thyroid carcinoma in patients with nodular thyroid diseases. Thyroid. 2001;11:73-80

61. Niccoli P, Wion-Barbot N, Caron P, Henry JF, de Micco C, Saint Andre JP, et al. Interest of routine measurement of serum calcitonin: study in a large series of thyroidectomized patients. The French Medullary Study Group J Clin Endocrinol Metab. 1997;82:338-41.

62. Costante G, Meringolo D, Durante C, Bianchi D, Nocera M, Tumino S, et al. Predictive value of serum calcitonin levels for preoperative diagnosis of medullary thyroid carcinoma in a cohort of 5817 consecutive patients with thyroid nodules. J Clin Endocrinol Metab. 2007:92:450-5.

63. Toledo SP, Lourenço Jr DM, Santos MA, Tavares MR, Toledo RA, CorreiaDeur JE. Hypercalcitoninemia is not pathognomonic of medullary thyroid carcinoma. Clinics (Sao Paulo). 2009;64:699.

64. Erdogan MF, Gursoy A, Kulaksizoglu M. Long-term effects of elevated gastrin levels on calcitonin secretion. J Endocrinol Invest. 2006;29:771.

65. Wang TS, Ocal IT, Sosa JA, Cox H, Roman S. Medullary thyroid carcinoma without marked elevation of calcitonin: a diagnostic and surveillance dilemma. Thyroid. 2008;18:889.

66. Dora JM, Canalli MH, Capp C, Puñales MK, Vieira JG, Maia AL. Normal perioperative serum calcitonin levels in patients with advanced medullary thyroid carcinoma: case report and review of the literature. Thyroid. 2008;18:895

67. Colombo C, Verga U, Mian C, Ferrero S, Perrino M, Vicentini L, et al. Comparison of calcium and pentagastrin tests for the diagnosis and follow-up of medullary thyroid cancer. J Clin Endocrinol Metab. 2012;97:905

68. Mian C, Perrino M, Colombo C, Cavedon E, Pennelli G, Ferrero S, et al. Refining calcium test for the diagnosis of medullary thyroid cancer: cutoffs, procedures, and safety. J Clin Endocrinol Metab. 2014;99:1656.

69. Costante G, Meringolo D, Durante C, Bianchi D, Nocera M, Tumino S Crocetti $U$, et al. Predictive value of serum calcitonin levels for preoperative diagnosis of medullary thyroid carcinoma in a cohort of 5817 consecutive patients with thyroid nodules. J Clin Endocrinol Metab. 2007;92:450.

70. Machens A, Hoffmann F, Sekulla C, Dralle H. Importance of gender-specific calcitonin thresholds in screening for occult sporadic medullary thyroid cancer. Endocr Relat Cancer. 2009;16:1291.
71. Chambon G, Alovisetti C, Idoux-Louche C, Reynaud C, Rodier M, Guedj AM, et al. The use of preoperative routine measurement of basal serum thyrocalcitonin in candidates for thyroidectomy due to nodular thyroid disorders: results from 2733 consecutive patients. J Clin Endocrinol Metab. 2011;96:75.

72. Machens A, Dralle H. Biological relevance of medullary thyroid microcarcinoma. J Clin Endocrinol Metab. 2012;97:1547.

73. American Thyroid Association Guidelines Task Force, Kloos RT, Eng C, Evans DB, Francis GL, Gagel RF, et al. Medullary thyroid cancer: management guidelines of the American Thyroid Association. Thyroid. 2009;19:565.

74. Kim SY, Han KH, Moon HJ, Kwak JY, Chung WY, Kim EK. Thyroid nodules with benign findings at cytologic examination: results of long-term followup with US. Radiology. 2014;271:272.

75. Nou E, Kwong N, Alexander LK, Cibas ES, Marqusee E, Alexander EK. Determination of the optimal time interval for repeat evaluation after a benign thyroid nodule aspiration. J Clin Endocrinol Metab. 2014;99:510.

76. Olson MT, Clark DP, Erozan YS, Ali SZ. Spectrum of risk of malignancy in subcategories of 'atypia of undetermined significance'. Acta Cytol. 2011:55:518.

77. Nayar R, Ivanovic M. The indeterminate thyroid fine-needle aspiration: experience from an academic center using terminology similar to that proposed in the 2007 National Cancer Institute Thyroid Fine Needle Aspiration State of the Science Conference. Cancer. 2009;117:195.

78. Ohori NP, Nikiforova MN, Schoedel KE, LeBeau SO, Hodak SP, Seethala RR, et al. Contribution of molecular testing to thyroid fine-needle aspiration cytology of "follicular lesion of undetermined significance/atypia of undetermined significance". Cancer Cytopathol. 2010;118:17.

79. Thyroid Carcinoma Task Force, American Association of Clinical Endocrinologists, American College of Endocrinology. AACE/AAES medical/ surgical guidelines for clinical practice: management of thyroid carcinoma. Endocr Pract. 2001;7(3):202-20

80. British Thyroid Association. Guidelines for the management of thyroid cancer in adults. London: Royal College of Physicians of London and the British Thyroid Association; 2001. [cited 2005 Aug 2]. Available at: http:// www.british-thyroid-association.org/Guidelines/.

81. Mazzaferri E. Thyroid cancer: impact of therapeutic modalities on prognosis. In: Fagin JA, editor. Thyroid cancer. Boston: Kluwer Academic; 1998. p. 255-84.

82. Schlumberger MJ. Papillary and follicular thyroid carcinoma. N Engl J Med 1998;338(5):297-306

83. Moon HJ, Kwak JY, Choi YS, Kim EK. How to manage thyroid nodules with two consecutive non-diagnostic results on ultrasonography-guided fineneedle aspiration. World J Surg. 2012;36:586.

84. Gharib H, Hegedüs L, Pacella CM, Baek JH, Papini E. Nonsurgical, ImageGuided, Minimally Invasive Therapy for Thyroid Nodules. J Clin Endocrinol Metab. 2013:98(10):3949-57.

85. Curtis RE, Rowlings PA, Deeg HJ, Shriner DA, Socie' G, Travis LB, et al. Solid cancers after bone marrow transplantation. N Engl J Med. 1997:336:25-904.

86. Won-Jin M, Jung Hwan B, So Lyung J, Dong Wook K, Eun Kyung Kim, Ji Young Kim, et al. Ultrasonography and the Ultrasound-Based Management of Thyroid Nodules: Consensus Statement and Recommendations. Korean J Radiol. 2011;12(1):1-14.

\section{Submit your next manuscript to BioMed Central and take full advantage of:}

- Convenient online submission

- Thorough peer review

- No space constraints or color figure charges

- Immediate publication on acceptance

- Inclusion in PubMed, CAS, Scopus and Google Scholar

- Research which is freely available for redistribution 